American Journal of Applied Sciences 2 (13): 78-80, 2005

ISSN 1546-9239

(C) 2005 Science Publications

\title{
Price-Taking in General Equilibrium
}

\author{
Murray C. Kemp \\ Macquarie University and Koji Shimomura, Kobe University, Japan
}

\begin{abstract}
The Arrow-Debreu and McKenzie existence propositions of 1954 rest on the assumption of price-taking behaviour by households and firms. No attempt was made to justify the assumption or to relate it to other assumptions. It is here suggested that, given other assumptions common to the ArrowDebreu and McKenzie models, price-taking implies that each household is incompletely informed and/or incompletely rational. By implication, complete information and complete rationality can be combined with price-taking only at the expense of internal consistency. On the other hand, given a suitable degree of ignorance and/or irrationality, both existence and the two fundamental welfare propositions remain intact.
\end{abstract}

Key words: Price-taking behaviour, internal consistency, general equilibrium

\section{INTRODUCTION}

For 80 years the Walrasian theory of general equilibrium suffered from a serious deficiency. It lacked an existence proposition. That deficiency was removed 50 years ago by the appearance of two remarkable papers ${ }^{[1,2]}$ and on those two papers most of us have since relied in our ventures into general equilibrium). Nowadays, however, the Arrow-Debreu and McKenzie papers are thought by some to be passe, mainly because of their assumption ${ }^{[3]}$ of non-strategic price-taking behaviour on the part of households and firms. On the other hand, it is not entirely clear why that assumption might now be unacceptable. The pioneering authors (Walras, ArrowDebreu and McKenzie) simply assumed price-taking, without justification or apology. Modem texts do address the issue, but without complete clarity. For example ${ }^{[4]}$ content themselves with the vague observation that.

... if market participants' desired trades are small relative to the size of the market, then they will have little incentive to depart from market prices. Thus, in a suitably defined equilibrium, they will act approximately like price takers. (Italics added.)

Our first purpose in the present study is to explain why the assumption of price-taking behaviour might be found to be unacceptable. The explanation proceeds by establishing that price-taking by households implies that each household is incompletely rational and/or incompletely informed about the economy of which it is part. It then follows that the assumption of price-taking is unacceptable if incomplete information and incomplete rationality are unacceptable. Our point is not that the assumption of price-taking is unrealistic in some sense. Nor do we suggest that the 1954 papers are logically defective. We suggest only that, when combined with other assumptions common to the two papers, the assumption of price taking implies incomplete information or incomplete rationality.

Our second purpose is to demonstrate, paradoxically perhaps, that if the Arrow-DebreuMcKenzie assumption of price taking is validated by the recognition of ignorance and/or irrationality, then their existence propositions, as well the two fundamental welfare propositions for competitive economies remain intact.

Throughout, our analysis will focus on the ArrowDebreu model. It might have been restricted to McKenzie's model, with the same outcome.

\section{ANALYSIS}

In any Arrow-Debreu ${ }^{[1]}$ economy:

- Households are finite in number

- Each household conceives of itself as a price-taker in all markets

- Each household seeks to maximize its own utility,

- The production set of each firm is convex and

- The endowment point of each household lies in the interior of its consumption set

However, if households are finite in number and if the endowment vector of each household lies in the interior of its consumption set then, in any equilibrium and in every market, each household exercises market power, directly and/or through firms in which it owns 
shares. That is, given the equilibrium net offers of all other households, any change in the net offer of households would disturb the set of market-clearing relative price vectors. Arrow and Debreu place virtually no restrictions on the distribution of endowments over households. Hence the extent of household's market power in equilibrium might be considerable. Or it might be very small-indeed it might approach zero as the number of households goes to infinity; but it cannot be zero for any finite population. Thus far, we are on familiar ground. However it immediately follows that, if it is perfectly informed and rational in the double sense that it seeks to maximize its own utility and can appreciate that (i) and (v) imply market power, then households cannot in equilibrium conceive of itself as a price-taker in every market. Thus we can state our first proposition.

Proposition 1: If the Arrow-Debreu model is internally consistent then each household must be incompletely informed and/or incompletely rational.

This suggests that the Arrow-Debreu analysis rests on an implicit understanding-that households are unaware that they are finite in number and/or are incompletely rational in the sense that they cannot appreciate that $(I)$ and $(v)$ imply market power. Without that understanding, assumptions $(i)-(v)$ would be mutually inconsistent. With that understanding and paradoxically, the familiar existence theorems and the fundamental welfare propositions remain intact.

Proposition 2: If households are unaware that they are finite in number and/or incompletely rational in the sense that they cannot appreciate that assumptions (i) and (jj) imply market power than existence is assured and the two fundamental welfare propositions of competitive economies remain intact.

Some post-1954 writers have sought to counter the problem of market power by assuming that all households are domestically price-takers but some firms are price-makers in some markets ${ }^{[5-7]}$. However all firms are owned by households; and given the convexity of production sets [(assumption (iv)], there is no reason why a firm cannot be owned by a single household. Why then should a household which is aware of its market power as a shareholder forget its power when it buys the household's groceries or sells the household's labour or other primary factors? To that question there appears to be no answer.

Others have sought to eliminate market power by assuming that the set of households forms a continuum of price-taking agents ${ }^{[9,10]}$ and the later developments of Aumann's ideas by Gabszewicz and Mertens $^{[11]}$ and Shitovitz ${ }^{[12]}$. To take that path, however, is effectively to assume away the problem posed in the present paper.

\section{FINAL REMARKS}

Bertrand Russell ${ }^{[13]}$ has remarked that "[ $\left.n\right] o$ one has succeeded in inventing a philosophy at once credible and self-consistent ${ }^{2}$. We have suggested that, for the consistency of the Arrow-Debreu and McKenzie models of competitive general equilibrium, it is necessary that, incredibly, each household is incompletely informed and/or incompletely rational. By way of contrast, we note that, for the consistency of oligopolistic general equilibrium, it is necessary that some but not all households be incompletely informed and/or incompletely rational; thus, without at least one price-taking consumer in its market, it is impossible to define a Cournot oligopolist's market power.

We focus on the best known of the four pioneering papers which, independently, resolved the existence problem. The less well known papers are Gale $^{[14]}$ and Nikaido ${ }^{[15]}$.

Russell added that Locke aimed at credibility and achieved it at the expense of consistency. Most of the great philosophers have done the opposite. A philosophy which is not self consistent cannot be wholly true, but a philosophy which is self-consistent can very well be wholly false. The most fruitful philosophies have contained glaring inconsistencies, but for that very reason have been partially true. There is no reason to suppose that a self-consistent system contains more truth than one which, like Locke's, is obviously more or less wrong.

\section{ACKNOWLEDGEMENT}

We acknowledge with gratitude the helpful comments of M. Ali Khan, Ngo Van Long and Peter Slezak.

\section{REFERENCES}

1. Arrow, K.1. and D. Gerard, 1954. Existence of an equilibrium for a competitive economy. Econometrica, 22: 265-290. http://www.stanford.edu/class/msande311/arrowdebreu.pdf 
2. McKenzie, L.W., 1954. On equilibrium in Graham's model of world trade and other competitive systems. Econometrica, 22: 147-161. http://www.abebooks.com/Equilibrium-

Graham\%C2\%92s-Model-World-Trade-

Competitive/5827186776/bd

3. Walras, L., 1874. Elements d'Economie Politique Pure. Lausanne: L. Corbaz.

4. Mas-Colell, A., D.W. Michael and R.G. Jerry. 1995. Microeconomic Theory. Oxford: Oxford University Press.

5. Gabszewicz, J.J. and V.J. Philippe, 1972. Oligopoly 'il la Cournot' in a general equilibrium analysis. J. Economic Theory, 4: 381-400. http://ferrari.dmat.fct.unl.pt/personal/mle/DocPDE GR/docsMF/GabszewiczJET1972.pdf

6. Roberts, J. and S. Hugo, 1977. On the foundations of the theory of monopolistic competition. Econometrica, 45: 101-113. http://www.jstor.org/stable/1913289

7. Hart, O.D., 1985. Imperfect Competition in General Equilibrium: An Overview of Recent Work. In: Frontiers of Economics, Edited by Kenneth $\mathrm{J}$. Arrow and Seppo Honkapohja. Oxford: Basil Blackwell.

8. Stahn, H., 1999. Monopolistic behavior and general equilibrium: A generalization of Nikaido's work. J. Mathem. Econom., 32: 87-112. DOI: 10.1016/S0304-4068(97)00067-0
9. Aumann, R.J., 1964. Markets with a continuum of traders. $\quad$ Econometrica, 32: 39-50. http://ideas.repec.org/a/ecm/emetrp/v41y1973i3p4 67-501.html

10. Aumann, R.1, 1966. Existence of competitive equilibria in markets with a continuum of traders. Econometrica, 34: 1-17. http://www.rand.org/pubs/research_memoranda/R M3853.html

11. Gabszewicz, J.J. and J.F. Mertens, 1971. An equivalence theorem for the core of an economy whose atoms are not 'too big'. Econometrica, 39: 713-722.

http://econpapers.repec.org/article/ecmemetrp/v_3a 39_3ay_3a1971_3ai_3a5_3ap_3a713-21.htm

12. Shitovitz, B., 1973. Oligopoly in markets with a continuum of traders. Econometrica, 41: 467-501. DOI: 10.1016/0022-0531(76)90078-8

13. Russell, B., 1946. History of Western Philosophy. London: George Allen and Unwin (1946, 2nd Ed. 1961). Quotation from 1991 reprint by Routledge, London.

14. Gale, D., 1955. The law of supply and demand. Mathematica Scandinavica, 3: 1-9.

15. Nikaido, H., 1956. On the classical multilateral exchange problem. Metroeconomica, 8: 135-145. 